\title{
The Effect of Communication on Individual Preferences for Common Property Resources: A Case Study of Two Canadian First Nations
}

\author{
William Nikolakis ${ }^{\mathrm{a}}$, Sonia Akter ${ }^{\mathrm{b}}$, Harry Nelson ${ }^{\mathrm{c}}$
}

${ }^{a}$ Forest Resources Management, University of British Columbia, Vancouver, BC, Canada. V6T 1Z4. Corresponding author: William.Nikolakis@ubc.ca Phone: +1 6048226509

${ }^{b}$ Lee Kuan Yew School of Public Policy, National University of Singapore, 469C Bukit Timah Road, Singapore 259772. Email: sonia.akter@nus.edu.sg.

${ }^{c}$ Forest Resources Management, University of British Columbia, Vancouver, BC, Canada. V6T 1 Z4.

"This is an Accepted Author Manuscript of an article whose final and definitive form has been published in Land Use Policy [December 2016] [copyright Elsevier], available online at: http://www.sciencedirect.com/science/article/pii/S0264837716306913."

[Please cite as "Nikolakis, W., Akter, S., Nelson, H. (2016) The Effect of Communication on Individual Preferences for Common Property Resources: A Case Study of Two Canadian First Nations, Land Use Policy 58: 70-82.’]

\section{Statement of authorship}

William Nikolakis co-ordinated the research project and wrote sections 1, 2, 3, 7 and parts of section 4 and 6. Sonia Akter designed the choice experiment, analysed the data and prepared sections 4 and 5 and wrote all of section 6. Harry Nelson contributed to sections 1, 2, 3, 6 and 7.

\section{Acknowledgments}

The authors would like to extend their thank you to the Ahousaht and Tla-o-qui-aht First Nations, in particular the assistance of Tyson Atleo, Saya Masso and Terry Dorward. The authors would also like to thank the Social Sciences and Humanities Research Council (SSHRC), Canada, for their support. 


\begin{abstract}
Increasingly, Indigenous Peoples are being re-empowered to make decisions about whether to approve development on their lands. But how these decisions are made has received little attention in the literature. Oftentimes, referenda or the solicitation of individual preferences through surveys may be used as input into the acceptability of proposed development. However, the focus on individuals does not necessarily incorporate how community members perceive the collective benefits associated with these land use decisions, nor recognize the collective deliberation procedures employed by many of these cultures. Drawing on the results from a choice experiment with two Canadian First Nations groups, this paper examines whether communication in a group-setting influences individual preferences for three land use alternatives: Industrial Development, Tourism Promotion, and Conservation \& Restoration. These alternatives had different economic and environmental attributes, expressed at more individual and collective levels. While respondents preferred land use alternatives that generated higher compensation and jobs, they preferred Conservation \& Restoration activities over Tourism Promotion and Industrial Development ranked last. Introducing communication in a group context led to a change in individual preferences, where respondents switched their votes from the other two alternatives to Tourism Promotion. The results offer important insight into the role of 'collective reflection' in research methods to assess Indigenous Peoples land use preferences, and for the design of nascent processes for Free, Prior and Informed Consent(FPIC).
\end{abstract}

Keywords: Indigenous Peoples; Common property resources; Generalized Mixed Logit; Communication and Group deliberation; Collective Action and Social Dilemma 


\section{Introduction}

Decisions over how to use common property resources too often lead to conflict and tension among affected populations. This is because decision makers typically come to decisions without involving affected peoples in any meaningful way, which fosters suspicion, conflict and litigation. Research shows that focusing on the structure of decision making processes, or how decisions are made, is crucial to mitigating conflict, and is more of a priority than what is decided; Wondolleck (1985) documents that when decision makers involve stakeholders in structured process to facilitate communication, to evaluate interests and alternatives, and in making trade-offs, that the decision tends to be supported, and consensus and mutual trust are built. While participatory processes and the importance of communication between the state and affected stakeholders have been well-documented in land-use literature, we understand very little about how the processes function within the context of Indigenous Peoples (IPs) and their own deliberations over land use.

Indigenous Peoples typically have a collective orientation, and unique norms, values and socio-economic context that are distinct from non-IPs populations. For instance, it has been shown that IPs tend to have more non-market values to land and resources than their non- IPs counterparts (Venn and Quiggin, 2004). Increasingly, IPs are being provided a collective right to decide on development in their territories. This study seeks to enhance understanding about how land use decisions and the associated trade-offs are evaluated by IPs in their decision-making processes for collectively held resources. The study pays particular attention to the issue of whether individual preferences for development (which has been the focus of previous assessments) are different when evaluated after communication in a group setting. The study helps answer these questions by applying the findings from a field experiment in British Columbia (BC), Canada. The experiment involved two First Nations groups, both of whom are faced with choices in reality between conservation and development in their territories, where the rights to lands and resources are held collectively and collective consent is increasingly a requirement in exploiting these resources.

Respondents were given a choice experiment where they could choose among different development options: Conservation \& Restoration; Industrial Development; Tourism Promotion; or if respondents do not prefer any of these three options they could vote for 'None', which we refer to as the Status Quo. A subset of the respondents had the opportunity to deliberate their choices collectively in a group setting. This group deliberation offers insight into how individual interests, reflected as payoffs and jobs to the First Nation (which the individual may obtain albeit indirectly), and the collective interest, such as access to territories and sustaining the environment, are mediated. We found that face-to-face communication in a group context caused members in those groups to change their individual preferences, reflected in a vote. This is the first time a choice experiment has been applied in this context of comparing individual preferences of IPs and the effect of face-facecommunication on these preferences. The findings from this study are of practical and theoretical importance.

\section{Background}

\section{1. Complex trade-offs in land-use decisions}

Industrial development and the exploitation of natural resources have had profound environmental and social impacts on IPs globally (Giddings et al., 2002). Indigenous peoples have typically borne the costs but gained few of the benefits from development, and because 
of this they have been described as the 'victims of progress' (Bodley, 1998). However, the issue of IPs preferences for development has taken on increased importance in recent years for three reasons. First, because advancements at international law to protect IPs and their rights has expanded their voice in decisions about natural resource extraction. This includes the International Labour Organization (ILO) Convention 169, and the United Nations Declaration on the Rights of Indigenous Peoples (UNDRIP, 2008). Among many things, the UNDRIP calls for good faith free, prior and informed consent (FPIC) to be obtained from IPs in resource development in their territories (Nikolakis et al., 2014; Nikolakis and Grafton, 2014). Second, non-state market driven governance mechanisms are legitimating norms and values to support FPIC among firms and NGOs, where domestic law does not support this requirement. Third, these shifts above have also been accompanied by legal decisions in many jurisdictions, policy changes and other actions increasing the amount of jurisdiction and land held by IPs.

This Indigenous right to decide development has been strongly contested by states and resource companies, but more recently in countries such as Canada, where the recent Supreme Court of Canada's Tsilhqot'in Nation decision and the commitment by the newly elected Federal government to implement the UNDRIP, ${ }^{1}$ means that consent has become a requirement, and now the state and firms must have a better understanding of what IPs want in terms of land use and the kinds of outcomes they prefer.

A key concern in implementing consent and FPIC regimes is around developing procedures that ensure integrity in reaching agreement on land use decisions, and to create decisionmaking processes that reflect the free will of each individual in the Indigenous collective. Increasingly, companies have been partnering with IPs to pursue economic development, and this is now recognized as a priority for Indigenous groups to achieve goals of self-governance and self-sufficiency (Anderson et al., 2006; Nikolakis, 2010). However, development can be contested within communities as there are tensions between development goals and the environmental and cultural impacts - thus reaching consensus within Indigenous collectives can be challenging (Wuttunee, 2004; Nikolakis and Nelson, 2015; Nikolakis and Grafton, 2015; Nikolakis et al., 2013). Where development involves natural resource extraction, such as mining or logging, it can create revenues for the community, employment for members but also creates trade-offs with cultural activities, like hunting and fishing and access to culturally significant sites. It is this choice between competing alternatives that Wuttunee (2004) describes as a paradox; for as Indigenous groups pursue development to improve their social outcomes there are the inevitable externalities that have social, cultural, spiritual and ecological impacts, which in turn, require further development and income to mitigate these problems. The duality of conservation and development, and the choice between either is not always clear, nor is it binary.

The collective nature of Indigenous lands and resource rights means that identity and collective orientation are important factors in decisions to manage these lands and resources. However, this collective orientation is surprisingly absent in studies investigating IPs perceptions and choices to land and natural resources. Implicitly, it is assumed that individual preferences in aggregate can be used to rank socially preferred alternatives for collectives

\footnotetext{
${ }^{1}$ Tsilhqot'in Nation v. British Columbia, 2014 SCC 44. In this case, the Supreme Court of Canada determined that the government should obtain the consent of Aboriginal groups where it will infringe on their land claims. There have also been decisions by superior courts across the colonized world that emphasise the importance of obtaining FPIC in development on Indigenous people's lands (Doyle, 2014).
} 
(Zander and Straton, 2010) and determine thresholds of acceptability for development (see Spyce et al., 2012). However, these studies offer a potentially incomplete picture, as these alternatives may not explicitly include collective outcomes, or allow individuals to collectively assess those alternatives against community aspirations. In this study, we present evidence that addresses this gap in literature by examining how individual preferences to common property resources are influenced by face-to-face communication in a group setting.

The two First Nations involved in the study, Tla-o-qui-aht and Ahousaht, are located in Clayoquot Sound on the West Coast of Vancouver Island, BC. Clayoquot Sound, is a designated UNESCO Biosphere Reserve that has some of the largest remaining stands of oldgrowth temperate rainforest in the world (Hayter and Barnes, 2012). During the last half of the $20^{\text {th }}$ Century, Clayoquot Sound was the scene of "one of the most heated and protracted environmental conflicts in Canadian history" (Lertzman and Vredenburg, 2005 p. 239) culminating in a truce of sorts in 1994. The truce resulted in a transfer of logging rights to local First Nations, which are an important economic driver for these communities. However, tourism has expanded in the region to become the economic lifeblood of Tofino, the regions hub, but these tourism businesses are typically non-First Nations owned, and tourism operations do not want First Nations logging to affect recreational and aesthetic values in Clayoquot. And recently, several large-scale mines have been proposed for the area, which has some groups concerned about the effect on social and ecological values. Clayoquot Sound has an important place in the imagination of Canadian society but it is also a working environment for First Nations and the resources sector. The problem lies in how to balance the multiple and oft-competing outcomes for tourism, industrial development and conservation land use across the region.

\subsection{Description of the First Nations}

Tla-o-qui-aht First Nation and Ahousaht First Nation are both autonomous members of the Nuu-Cha-Nuulth Tribal Council and Nuu-Cha-Nuulth language group residing side-by-side in Clayoquot Sound. Both First Nations are subject to the Indian Act, a complex piece of legislation that governs First Nations across Canada and their reserve lands. Reserve lands are inalienable lands that are held collectively by First Nations, many of whom may also reside on these lands. These First Nations also have rights to land and water that the Crown asserts sovereignty over, which may include the need to obtain the First Nations' consent for land use decisions.

While the two First Nations have reserve lands, there has been a migration of community members living off-reserve, a trend evinced across BC where people have sought to find better employment and education opportunities (Wilson and Peters, 2005). Please see Appendix A for demographic statistics for both First Nations.

Evidence shows that both First Nations have been living side-by-side in the Clayoquot Sound region for millennia. The perspective of Hishuk ish Tsawalk, 'everything is one and all is interconnected', and Iisaak, 'a respect for all living things', are driving principles and values for the Nuu-cha-nuulth worldview (Atleo, 2007). Both First Nations have been able to demonstrate a strong claim for collective Aboriginal rights and title in their territories, which has been contested by the Crown who claims sovereignty to these territories. Both First Nations are actively seeking to regain control over their land base and self-governance. However, in order to regain self-governance, the First Nations must have revenues to support service delivery, as well as sufficient revenues to manage their land base effectively. In terms of economic development, both the First Nations own and operate a logging company 
together; both have also been subject to the impacts of industrial forestry, as well as mining proposals; and both First Nations are largely excluded from the tourism sector, but Tla-o-quiaht is impacted more by tourism (in a terrestrial sense) as the resort hub of Tofino is located in their territories.

Both First Nations are formally governed by an elected Chief and Council system under the Indian Act. The Chief and Council are elected by constituents in a secret individual ballot. The elected Chief and Councillors are empowered to make land use decisions, but plebiscites are also used to make important land use decisions and these decisions are typically discussed collectively in 'community meetings'. Traditionally both First Nations were governed by a hereditary chief system. A hereditary chief is called a $\mathrm{Ha}$ 'wiih. Hereditary chiefs (plural Ha'wilth) were responsible for governing their Hahoulthee (ancestral territory and natural resources) and the members of their 'House' called Muschim (citizens). In effect the Ha'wiih were stewards of the Hahoulthee and the Muschim benefited under this rule and stewardship by accessing the Hahoulthee for food, water, fibre, materials and medicines (Masso, 2005). The hereditary chiefs still play a role, both formally and informally, in governance, though this co-existence can sometimes be uneasy. The influence of hereditary chiefs is particularly important on land management decisions.

\section{Literatures}

\subsection{The role of communication in managing common property resources, social dilemmas and public goods}

Often the sustainable and efficient use of common property resources, such as forests, fisheries and irrigation systems, is framed as one requiring individuals within a group to make decisions and cooperate about the extractive use of the resource. Resource users then face 'social dilemmas' in making decisions due to perverse incentives invoked by biophysical, social and economic factors (Cárdenas and Ostrom, 2004), where "individuals make independent choices in an interdependent situation" (Ostrom, 1998). Under a rational economic perspective, an individual will make choices that seek to maximise their short term self-interest, and when these individual interests run counter to the interests of the collective it can lead to conflict and a Pareto inferior outcome. The optimal outcome can only be achieved when the individuals involved in a group cooperate in forming a mutually agreeable decision (Ostrom, 1998).

Economic experiments have been extensively used to understand decision-making heuristics and cooperation in the context of social dilemmas and have consistently found that face-toface communication is the most powerful factor in determining cooperation among individuals (Ostrom, 1998; Ostrom, 2006). A meta-analysis that involved more than 100 experiments and 5,000 subjects found that the opportunities to communicate face-to-face increases the cooperation rate by more than 45 percentage points in a one shot game and 40 percentage points in a repeated game (Sally, 1995). Kerr and Kauffman-Gilliland (1994) also found that intra-group communication promotes cooperation in social dilemmas.

These models of communication of the "social dilemma" is solved, however, rely on individuals recognizing it is in their self-interest to cooperate. Any benefits that accrue to the larger group are a by-product of this rational calculation. However, Ostrom and others have noted that this may be too limiting in how it views human motivation, where individuals may have broader range of factors influencing their decisions beyond this simple calculus. In these models, respondents may be motivated by altruism or resolving the public goods problem, in 
which rational individuals face the incentive to free ride, letting others bear the cost of providing these goods (Ostrom 2010; Shogren). While there are aspects of public goods to the question we are investigating, it is more complex in this study context. While there is publicly expressed interest in acting collectively, related to an evolving expression of collective self-identification, there are also concerns as to whether or not these institutions can deliver such outcomes. In the broader context of First Nations in Canada, these collective goals are economic (generating revenue), social (self-sufficiency) and ensuring cultural integrity, while institutions are challenged by political instability, low levels of trust and socio-economic disadvantage. (Experiments with public goods and communication? A priori there may or may not be a change after communication-can still be rational to free ride). It is this aspect of decision-making in which we are interested, in which these two First Nations are actively rebuilding their governance institutions, to see how this is expressed in terms of individual preferences versus collective outcomes, and whether (as hypothesized) communication may play a role in how individual perceive the relative importance of those goals and associated trade-offs.

Wondolleck and Yaffee (2000) observe that competing resource users will collaborate where they can communicate in a structured way. Communication enables different parties to share their worldviews, interests and opinions (cognitive models and heuristics), generating social and political learnings. These collaborations can establish new shared cognitive models and decision making heuristics between these disparate groups (Wondolleck and Yaffee, 2000). However, in this study we examine within-group communication among a population distinct to that observed by Wondolleck and Yaffe, (2000), whom have a shared identity and collective orientation that makes evaluation of these decision making processes novel.

Evidence shows that individuals will change their decisions when in group settings, for example, Dion et al. (1970) document that groups will make riskier decisions than individuals, and Janis $(1971 ; 1982)$ observes a groupthink phenomenon, where group members will seek to conform in their decision making. There are a number of theories that seek to explain how communication facilitates consensus in a group setting, including the 'persuasive arguments theory', where the persuasive process influences a shift in choice among individuals; the 'social comparison theory', where individuals will define/evaluate their own opinions by comparing these against others in the group (Burleigh and Meegan, 2013); and, the 'purposive action theory' which provides that decisions that are collective in nature are driven by complex motivators (Coleman, 1966), like reputation (Fehr, 2004), 'social influence' (Turner, 1991), and group cohesion and norms (Postmes et al., 2001).

\subsection{Choice experiment}

In a choice experiment research design, respondents are asked a series of questions in which a unique set of alternatives, or a scenario, is presented each time. Random utility theory suggests that individuals obtain utility from the specific attributes that make up a scenario, rather than deriving satisfaction from the scenario itself (Fishburn, 1988). Attributes in each scenario can include income, employment, land access or ecological outcomes. Inferences can be made from the level of utility gained by individuals from the attributes favoured in each scenario, which can be predictive of a person's behaviour, particularly as it relates to people making trade-offs between competing land and resource management alternatives (Gregory, 2000). The answers from choice questions demonstrate that when individuals repeatedly chose between different alternatives, their preferences are stable enough to construct measures on public preferences for land and resource management outcomes 
(Louviere et al., 2000). Such measures can then guide policy development and decisions over land and resource management.

The use of choice experiments to understand IPs preferences between development and conservation has received limited attention, with less than a handful of studies (Spyce et al., 2012; Zander et al., 2013). These studies have typically involved both Indigenous and nonIndigenous groups, and the comparisons focus on different preferences between these groups for different land management outcomes (Spyce et al., 2012; Zander et al., 2010; Zander and Straton, 2010; Zander and Garnett, 2011). The results from these studies show a general preference for conservation among Indigenous and non-Indigenous peoples alike, suggesting shared socio-cultural norms and values for conservation.

Spyce et al., (2012) in their choice experiments in Yukon, Canada, found there was little heterogeneity between the preferences for development and conservation among Aboriginal $(n=67)$ and non-Aboriginal peoples $(n=129)$, and that, in aggregate, a strong conservation scenario was ranked highest by both groups. However, there was significant variation in support for conservation attributes: so while employment was stable in respondent's rankings, the conservation scenario varied in rankings. There was also a higher preference for a strong development scenario than medium development meaning there were no social thresholds placed on development. But, all respondents placed a slightly negative discount rate on development, suggesting they favoured intergenerational equity, which has been identified as a signature value of IPs in previous research (Gregory and Trousdale, 2009).

In Australia, a series of choice surveys, involving both a mixture of face-to-face and mail out approaches, were conducted of individual Indigenous and non-Indigenous Australians, with a focus on the management of tropical rivers in northern Australia (Zander et al., 2010; Zander and Straton, 2010), and to understand the public's willingness to pay for IPs to directly engage in natural resource management (NRM) activity across the tropical northern savannas (Zander and Garnett, 2011). In terms of managing north Australia's rivers, a conservation focused approach was preferred by most respondents: Indigenous respondents were indifferent to water extraction for irrigated agriculture while non-Indigenous Australians preferred moderate development to low or high development scenarios (Zander and Straton, 2010). Zander and Garnett (2011) sought to understand the public's willingness to directly pay for IPs to engage in NRM, and they found that most respondents were willing to pay for this, primarily to enhance biodiversity, reduce carbon emissions and to manage feral animals. But paying IPs to engage in NRM for the social benefits was not a significant motivator for respondents (Zander and Garnett, 2011).

Rolfe and Windle (2003) using a choice experiment sought to estimate the non-use values of Indigenous cultural heritage protection in the Fitzroy Basin in central Queensland. Three groups were sampled: IPs in the Rockhampton region, and general populations from Rockhampton and Brisbane (the state's capital). What was found, perhaps unsurprisingly, is that IPs valued the protection of cultural heritage values more than the general population groups, who were focused on environmental values.

\section{Materials and methods}

\subsection{The experimental design}

A choice experiment was designed to understand First Nations preferences for land use alternatives in Clayoquot Sound. In each choice question respondents could choose between Industrial Development, in which there was a substantial negative impact on local 
ecosystems; Tourism Promotion, with a small negative impact on local ecosystems; and Conservation \& Restoration, with a substantial positive impact on local ecosystems. Each alternative had different levels of economic activity and restrictions on access to the land base. If the respondent did not agree with any of the proposed alternatives or was unsure they could chose 'none,' which means they preferred the Status Quo. These alternatives reflect the different alternatives open to the First Nations in this setting, where mining development has been proposed in their respective territories, as have conservation-based projects as well as the opportunity to participate in the tourism-based regional economy.

The attributes used in this experiment were: Jobs to the Nation's members; Compensation (a yearly payment to the Nation); Contract duration; and land use Restriction. Table 1 lists the attributes and their levels, as well as the sources of attributes in literature. Alternative specific attribute levels were chosen to reflect the difference of attribute natures across alternatives. Industrial Development was characterized by a relatively higher range of compensation and full-time jobs as opposed to a Conservation and Restoration program that involves relatively lower compensation and seasonal jobs. Conservation and Restoration involved a relatively longer contract duration compared to Industrial Development and Tourism Promotion, reflecting the nature of such projects. Tourism Promotion was moderate with respect to both compensation and jobs (part-time). Compensation would not be directly received by the community members but would go to the collective, but the individuals would obtain the indirect benefits such as improved education, health services and infrastructure. Jobs, Compensation and Contract had alternative specific levels. Land use Restriction was a generic attribute.

\section{INSERT TABLE 1 HERE}

To ensure the land use options, scenarios, attributes and attribute levels were realistic, the researchers pre-tested these among a select group of community liaison staff at the two First Nations; as well as First Nations cohorts at the University of British Columbia (all of which have worked in land use and natural resource management roles in this context); and a select group of experts in the region (from NGOs and industry).

A provision rule is important to a choice experiment as it provides incentives for truthful preference revelation by explicitly mapping responses to actual policy outcomes (Collins and Vossler, 2009). We used a straightforward plurality vote implementation rule that indicated that the option that receives the highest votes will be implemented for the whole group (Collins and Vossler, 2009). Plurality voting is the most commonly used provision rule in stated choice experiment survey. This rule was also easy to explain to our respondents as it is commonly used to make decisions within the First Nations. Another important reason for using the plurality rule is that under this provision rule the incentive compatibility property of a three-option choice experiment does not differ from a two-option or dichotomous choice referendum type elicitation method (Collins and Vossler, 2009). ${ }^{2}$

Following the guidelines outlined in Hensher et al. (2005) and Bliemer et al. (2008), an alternative specific (or labelled) 'Db-optimal efficient design' was constructed in Ngene software. The generation of an efficient experimental design requires a priori knowledge of the parameter values. Information about these 'priors' were collected from the existing literature (Table 1) then validated with experts. Inaccurate prior values may cause an

\footnotetext{
${ }^{2}$ A binary discrete choice elicitation format with a plurality vote implementation rule is incentive compatible (Carson and Groves, 2007).
} 
efficiency loss by increasing the value of the D-error. However, a Bayesian efficient design (also known as a Db-optimal design) allows the researcher to incorporate information from an a priori distribution of parameters and hence is less sensitive to prior values and model misspecification (Bliemer et al., 2009).

The experimental design had 18 choice combinations randomly divided into three blocks. Each respondent was asked six choice questions. Figure 1 presents an example of a choice question. The order of appearance of the choice questions, the position of the attributes and the alternatives were randomized across respondents to control for potential order bias. A scenario description was presented before introducing these questions. The description contained a qualitative explanation of each land use alternatives and their corresponding payoffs to the First Nation (Appendix B).

\section{INSERT FIGURE 1 HERE}

\subsection{The experiment}

An experiment was designed using a treatment and control setting to allow 'pre-post' and 'with-without' communication comparisons across three respondent groups ${ }^{3}$ (see Table 2 and Appendix C). Respondents were first asked to complete six unique choice tasks (Round I). Then they were given 20 minutes to reflect on their choices. After 20 minutes, the treatment groups were able to discuss their choices with their fellow group members, while the control group respondents were not allowed to communicate with others. Both treatment and control groups were then asked to complete the entire sequence of the six choice questions again (Round II). This resulted in 12 choice sets per respondents.

\section{INSERT TABLE 2 HERE}

A structured questionnaire survey was administered in Rounds I and II. The questionnaire used during Round I contained 30 questions and was divided into three sections. The first two sections comprised socio-demographic and attitudinal questions, such as respondents' age, sex, education, income and their perceptions of ecological risks and the relative importance they attach to different land use outcomes. The third section included the choice questions. Round II of the questionnaire contained 14 questions, including the repeated choice questions, followed by 8 questions on social cohesion, including trust and confidence in their community and First Nations Council.

Two in-depth key informant interviews were administered with elected leadership. The questions asked for information on important characteristics for their First Nation such as: the electoral system; the level of difficulty in leaders fulfilling their responsibilities; the nature of disputes and who resolved them; key norms; sanctions for breaking norms; levels of trust and cooperation; and economic data such as unemployment and the number of members living below the poverty line.

\subsection{Utility framework}

The underlying structural model encompassing the discrete choice behaviour is called the 'random utility maximization model'. Due to unobservable effects, (indirect) utility is

\footnotetext{
${ }^{3}$ There were three discrete groups involved in experiments. One on-reserve Tla-o-qui-aht group. The second was an Ahousaht on-reserve group. The third was an Ahousaht off-reserve group.
} 
partitioned in to an observable $(V)$ and an unobservable part $(\varepsilon)$ for each alternative $(k=1,2,3,4)$. Thus:

$$
U_{i k}=V_{i k}+\varepsilon_{i k}
$$

In this study, the observed component of the indirect utility function of an individual i takes the following form:

$$
V_{i \mathrm{k}}=A S C_{i k}+\beta_{i k} \text { Pay-off } i k+\alpha_{i k} \text { Treatment }
$$

In Equation 2, $A S C$ stands for alternative specific constant. Since an alternative specific (or a labelled) experiment was used, the indirect utility function contains three constants including one constant for each land use alternative (Hensher et al., 2005). The ASC variable absorbs and isolates the (non-zero) mean utility associated with unobserved attributes of the land use alternatives that are not explicitly included in the choice experiment such as the implicit environmental impacts associated with tourism versus industry. Our experiment involves three non-monetary payoffs (jobs, restriction and contract duration) and one monetary pay-off (compensation). Separate utility parameters are assigned for jobs and compensation to account for their alternative specific nature. Jobs in Conservation \& Restoration are part-time and seasonal, while Tourism related jobs are full-time but are seasonal. Industrial Development jobs are full-time and available all year round. As for compensation, the amount of compensation offered to the community for Industrial Development projects are relatively higher than the Tourism and Conservation \& Restoration projects. Contract duration and land use restriction are treated as generic attributes.

$\alpha$ estimates the treatment effect in the model that measures the mean difference in utility between the treatment and control groups across the land use alternatives. A naïve approach to estimate $\alpha$ would be to simply combine the treatment and control samples and employ a standard random parameter logit model technique. However, the noise or scale parameters, or the inverse of the standard deviation of the error tem $\varepsilon_{i k}$, from the treatment and control data are likely to be different due to the different setting used for the data collection process (Swait and Louviere, 1993). For example, one can argue that the treatment data contains more (or less) noise as it allowed respondents to communicate and vice versa. The difference in the scale parameter will cause the estimated model coefficients to differ across the treatment and control datasets leading to biased conclusions about the influence of communication on land use preferences. Hence, controlling for scale heterogeneity across the two datasets is critical.

A generalized mixed logit (GML) model $^{4}$, proposed in Fiebig et al. (2010), is used for data analysis as this model allows to control for both preference and scale heterogeneity across individuals as well as across different datasets. In a GML model (Green and Hensher, 2010):

$$
\beta_{i}=\sigma_{i}\left[\beta+\theta \mathrm{z}_{i}\right]+\left[\gamma+\sigma_{i}(1-\gamma)\right] \Gamma v_{i}
$$

In equation $3, \sigma_{i}$ is the individual specific standard deviation of the idiosyncratic error term such that $\sigma_{i}=\exp \left(-\tau^{2} / 2+\tau w_{i}\right)$, where $\tau$ is the coefficient on the unobserved scale heterogeneity and $w_{i}$ is the unobserved heterogeneity $\left[w_{i} \sim \mathrm{N}(0,1)\right] . \mathrm{z}$ is a set individual

\footnotetext{
${ }^{4}$ An important property of this model is that it avoids the IID assumption (i.e. the error tem is independently and identically distributed) and thus allow attributes to be correlated across alternatives (Fiebig et al., 2010).
} 
specific characteristics that influence the mean of the preference parameters, $\theta$ is a vector of parameters, $v$ is the error term with zero mean and known variance, $\Gamma$ is the lower triangular Cholesky matrix. $\gamma$ is a weighting parameter varying between 0 and $1 . \gamma$ determines the relative importance of the overall scaling of the utility function versus the scaling of the individual preference weights contained in the diagonal elements of $\Gamma$ (Green and Hensher, 2010).

In equation $3, \tau=0$ implies $\beta_{i}=\beta+\Gamma \mathbf{w}_{i}$ which is the random parameters logit model specification which accounts for only preference heterogeneity. Since the scale heterogeneity in our sample is dataset specific, a dataset-specific covariate of mean scale is needed to control for the possible noise led by the presence (or absence) of communication. Following Hensher et al. (2011), we model $\tau$ by using a dummy variable such that: $\tau=\tau+\eta$ *Treatment where $\eta$ is a dataset specific scale parameter and Treatment $=1$ for the treatment sample and zero otherwise.

\subsection{Sampling}

Respondents were randomly selected by a liaison officer in the First Nation from the members list and personally invited to attend the survey on the day scheduled. Transportation was arranged to mitigate respondent inconvenience. Where the individual could not attend, another individual was selected and invited to attend. In total 104 surveys were completed and of these 97 were usable. Of the 97 surveys completed, 25 were from Tla-o-qui-aht (representing 12.5 percent of the total voting age population for Tla-o-qui-aht), and 75 were from Ahousaht, of which 32 were surveyed on-reserve in Ahousaht ( 8 percent of the total voting age population on-reserve), and 43 from off- reserve in Port Alberni and Victoria (5 percent of the total voting age population off-reserve). A comparison of respondents' sociodemographic characteristics in each community is available in Appendix D.

\section{Group cohesion, trust and norms}

From the two in-depth key informant interviews it is observed the two First Nations varied with respect to group cohesion. In response to the question, 'how often do wealthier households help poorer households?' one key informant answered 7 out of 10 (10 being “All the time"), while the other informant ranked it lower, at 3 of 10 (1 being "Not at All"). However, in terms of direct responses from respondents, we observed no differences between the two First Nations, where trust was equally quite low. In the survey questionnaires slightly over a quintile (22\%) of the sampled respondents agreed (or strongly agreed) with the statement "Trust is strong in my First Nations" but over half $(52 \%)$ of the sampled respondents disagreed with the statement, while the rest (26\%) neither agreed nor disagreed. A similar trend was observed with the statement "I have full confidence in my First Nations council's ability to make the right decision for its people", for which 37 percent disagreed, 40 percent neither agreed nor disagreed and 23 percent agreed. As expected, the level of trust among the community members and community leadership were highly positively correlated $(\mathrm{r}=0.50, p<0.001)$ implying a higher trust among the community members is likely to be associated with a higher trust on community leadership.

Group cohesion was closely and positively linked with trust. Respondents who strongly agreed with the group cohesion statement, "I could rely on my community and council members in case of crisis and emergency", were also more likely to agree with the statements "Trust is strong in my First Nations" $(\mathrm{r}=0.40, p<0.001)$ and "I have full confidence in my First Nations council's ability to make the right decision for its people" $(\mathrm{r}=0.57, p<0.001)$. 
For both Tla-o-qui-aht and Ahousaht, respect for culture and environment were two of the key norms by which the communities are governed. Conformity to these norms was reflected through respondents placing a higher value on cultural and environmental preservation as a land management outcome. Almost three quarters $(72 \%)$ of the respondents placed the highest value on culture, followed by 60 percent of the respondents who prioritized environment the most, while a quarter of the respondents believed culture and environment are inseparable. No significant differences were observed between Tla-o-qui-aht and Ahousaht respondents living on-reserve with respect to the way they valued culture and environment.

Conformity to norms and perceived ecological risks were found to be significantly and positively correlated. Particularly, those respondents who placed a higher value on the environment, were more likely to believe that the ecological assets such as forests $(\mathrm{r}=0.37$, $p<0.001)$, fisheries $(\mathrm{r}=0.24, p<0.001)$ and wildlife $(\mathrm{r}=0.32, p<0.001)$ are at a high risk of extinction. They were also more likely to perceive a high threat to Indigenous cultural integrity $(\mathrm{r}=0.26, p<0.001)$.

\section{Results}

\subsection{Votes for land use alternatives}

Figure 2a summarizes the proportion of votes received by each of the land use alternatives in the overall sample across Rounds I and II. In general, Conservation \& Restoration was the most preferred land use option (42\% of votes), followed by Tourism Promotion (34\% of votes) in Round I. Both Industrial Development and Status Quo were among the least preferred alternatives, receiving 12 percent of votes each. The distribution of the preferred alternative in Round II changes as support from Conservation \& Restoration and Industrial Development declined and support for Tourism Promotion increased. Figure $2 b$ shows the percentage change in votes among different alternatives across the treatment and control groups between Rounds I and II. No substantial shift in voting occurred for the control group in Round II. The proportion of the total votes received by Conservation \& Restoration and Industrial Development remained unchanged while Tourism Promotion received 2 percent less votes and the Status Quo received 2 percent more votes in the control group. For the treatment group, the changes in voting intention between Rounds I and II are substantial. In Round II, votes declined from Status Quo, Industrial Development and Conservation \& Restoration by 7 percent, and increased for Tourism Promotion by 7 percent.

\section{INSERT FIGURE $2 \mathrm{a}$ and $2 \mathrm{~b}$ HERE}

Significant preference heterogeneity was observed across the First Nations (Figure 3). On average, in both Rounds I and II, respondents from Ahousaht were significantly more likely to vote for the Status Quo and Industrial Development and less likely to vote for Conservation \& Restoration (Chi Square $=41, p<0.001$ ). Further, a significant divide persisted between the on- and off-reserve Ahousaht members. Respondents who lived offreserve significantly favoured maintaining the Status Quo as opposed to undertaking any development activity (Chi Square=27, $p<0.001$ ). No significant difference in land use preference was observed between the on- and off-reserve respondents in terms of the nonstatus quo options.

\section{INSERT FIGURE 3 HERE}

\subsection{Choice experiment results}


Table 3 presents the GML regression results obtained from the combined observations of the treatment and control samples. ${ }^{5}$ The GML model was estimated in NLOGIT version 5.0, accounting for the panel data structure of the choice questions. The model is significant with a pseudo $\mathrm{R}^{2}$ value of 40 percent. The estimated coefficient of the scale variance $(\tau)$ is significantly different from zero implying the presence of significant scale heterogeneity in the sample. The significant negative coefficient of $\eta$ indicates that the preference of the treatment sample is associated with lower scale variance than the control sample. This means that the respondents' choices in the treatment sample is less random. Given that sampling was random, this difference in scale can be attributed to communication.

The results presented in Table 3 shows the respondents preferred land use alternatives that were associated with higher compensation, lower restriction, longer contracts and higher jobs. This finding suggests trade-offs are most acute between livelihood outcomes and access for traditional purposes.

\section{INSERT TABLE 3 HERE}

$\beta_{\mathrm{ASC}(\text { Conservation), }}, \beta_{\mathrm{ASC}(\mathrm{Tourism})}$ and $\beta_{\mathrm{ASC}(\text { Industry) }}$ estimate utility obtained from the specific nature of the land use options independent of the attributes. This may reflect respondents' preferences for the environmental impacts associated with these alternatives and other unobservable factors that are not captured by the choice experiment attributes. These coefficients were treated random using a normal distribution. The mean utility associated with Tourism Promotion $\left[\beta_{\mathrm{ASC}(\mathrm{Tourism})}\right]$ is positive and Industrial Development $\left[\beta_{\mathrm{ASC}(\text { Industry) }}\right]$ is negative. Both coefficients are significantly different than zero. The mean utility gain from Conservation and Restoration $\left[\beta_{\mathrm{ASC}(\text { Conservation })}\right]$ is positive but not significantly different than zero implying that the sampled respondents' utility gain (loss) from Conservation and Restoration independent of its monetary and non-monetary pay-offs, are not significantly different than the utility of the Status Quo. Respondents viewed Tourism Promotion as an improvement over the Status Quo.

The estimated standard error of $\beta_{\mathrm{ASC}(\mathrm{Conservation})}$ and $\beta_{\mathrm{ASC}(\text { Industry) }}$ are significant at the one percent level reflecting significant preference heterogeneity among respondents regarding the two land use options, Conservation and Restoration, and Industrial Development. Interestingly, the estimated standard error of $\beta_{\mathrm{ASC}(\mathrm{Tourism})}$ is not significant at the ten percent level implying the absence of preference heterogeneity regarding Tourism Development.

Six variables were included in the regression model to test for (1) 'before-after' and (2) 'with-without' effects. The first three variables test the before-after effect between Rounds I and II. None of the coefficients of the three interaction effects were significantly different than zero implying no significant difference in respondents' voting intentions between Rounds I and II. The remaining three variables measure the effect of communication (i.e. treatment effect) in Round II. The coefficients of Round II*Treatment*Tourism is positive and significant at the five percent level. This means the respondents in the treatment groups

\footnotetext{
${ }^{5}$ Before proceeding to the GML model, a Swait-Louviere test for equality between attribute parameters was performed comparing the pooled model with two separately estimated models (Swait and Louviere, 1993). The value of the chi-squared test statistic was 27 (degrees of freedom=12) which means that the null hypothesis of equal attribute parameters was rejected at the one percent level of statistical significance. This means that the attribute parameters in the treatment and control data sets are significantly different but given that the scale and attribute parameters are confounded, it is not possible to disentangle the differences in either the beta parameters alone or the beta and scale parameters (Louviere et al., 2003).
} 
were significantly more likely to choose Tourism in Round II compared to those who were in the control groups. The mean coefficients of Round II*Treatment*Industry is negative and Round $I I^{*}$ Treatment $*$ Conservation is positive but none of the mean coefficients are statistically significant at the ten percent level.

\subsection{Implicit Prices and Compensating Surplus (CS)}

Implicit prices, also known as part-worth or marginal willingness to pay/accept, were estimated using the parameter estimates obtained from a main-effect model (Appendix E). The following formula was used:

$$
\text { Implicit Price }=-1 *\left(\frac{\beta_{j}}{\beta_{\text {monetary }}}\right)
$$

where $\beta_{j}$ is the coefficient of the non-monetary attribute obtained from the utility model and $\beta_{\text {monetary }}$ is the estimated coefficient of the monetary attribute. The estimated implicit prices of Jobs, Contract and Restriction and their 95 percent confidence intervals estimated using Wald procedure (Delta Method) are presented in Table 4.

\section{INSERT TABLE 4 HERE}

Compensating surplus (CS) is the amount of income paid or received that leaves households at the initial level of well-being. CS can be obtained by using the following equation for different land use options:

$$
C S=(-1) * \frac{V_{0}-V_{1}}{\beta_{\text {monetary }}}
$$

Where $\mathrm{V}_{0}$ and $\mathrm{V}_{1}$ represent the conditional indirect utility associated with the Status Quo and the changed situation respectively. Since the Status Quo alternative in our experiment was defined as None, this means $V_{0}=0$. Compensating surplus thus only represents the conditional indirect utility $\left(V_{1}\right)$ obtained from each land use option. In order to estimate and compare CS of the presented land use options, the following hypothetical values were assigned to the attributes of all alternatives: Jobs=3; Contract $=30$ years; Restriction=Low. Note that these numbers are used strictly for illustration purpose. The implicit prices can be used to compute CS under a large number of different scenarios where the attribute levels of the land use options may or may not coincide.Table 5 presents the CS estimates and their 95 percent confidence intervals. The CS values estimated for Conservation \& Restoration is negative and Tourism Promotion is positive. They are statistically significant at the five percent level. The CS estimated for Industrial Development is negative but not statistically significant at the five percent level. These imply a significant welfare gain can be achieved from Tourism Promotion, while Industrial Development and Conservation \& Restoration are likely to cause welfare loss on the First Nations.

\section{INSERT TABLE 5 HERE}

\subsection{Research Limitations}

Generalizing the findings from this study is limited beyond this unique context because of the sample size. There are also two sources of bias that should be acknowledged when interpreting the results, though the researchers actively sought to mitigate these in the 
research design. The first is social desirability bias in a group setting, where individuals alter their answers to appease others in the group as well as the researchers. By providing anonymity to respondents when answering the survey in both the with-communication and without-communication groups, we mitigated social desirability bias. We also asked respondents how certain they were with their decision in each choice question to offer insight into the level of certainty in the response (see Figure 1). The second is hypothetical bias, or the degree to which the hypothetical nature of the choice experiment influenced respondent's answers. We sought to mitigate this bias by producing scenarios, attributes and attribute levels in collaboration with community liaison staff and experts that reflected those in reality.

\section{Discussion and conclusions}

The first study objective was to understand respondents' land use preferences and what attributes are important to them. While respondents ranked Conservation \& Restoration highest, followed by Tourism Promotion and Industrial Development, the results also show land use preferences were not polarized around either development or conservation, but that individually respondents preferred land use alternatives that generated higher economic outcomes similar to that found by Spyce et al. (2012) in Yukon among Aboriginal and nonAboriginal peoples. The socio-economic disadvantage in First Nations communities, particularly for those living on-reserve, likely underpins this desire for livelihood outcomes where these are circumscribed; conversely, we found those respondents who live off-reserve, where there are more employment and education opportunities, significantly favoured maintaining the Status Quo rather than pursuing development opportunities.

The second study objective was to determine whether or not group communication affected an individual's preferences, or voting intentions, for a land use alternative. Consistent with the theoretical expectation and empirical evidence from literature, our findings demonstrate that individuals will change their preferences where there is communication in a group context. Respondents' with-communication were more likely to switch their vote to Tourism Promotion, and their choices were less random than the control group. Previous empirical work offers that communication enables cooperation among disparate groups and individuals in collaborative decision making processes, typically between the state and stakeholders. This is because these groups can share their opinions and worldviews, evaluate the alternatives, and decide among trade-offs in a transparent way, which generates social and political learnings and builds trust between parties (Wondolleck, 1985). We hypothesise that group communication helps mediate between the interests of individuals and the collective when IPs make collective land-use decisions - helping resolve a collective action dilemma around the appropriateness of collective outcomes to individual members. Group communication offers a mechanism to inform individual members of the collective of the land-use trade-offs and alternatives, and may foster a convergence or social-equilibrium on land-use decisions. Group communication also provides an opportunity to re-affirm collective values, like in this context 'Hishuk ish Tsawalk' which means 'everything is connected'. Values like 'Tsawalk' can offer a means of social control, to guide land use decisions, encourage sustainable use of collective resources, and offers constituents a basis for evaluating collective decisions. Land use decisions that run counter to these values may lack social legitimacy, and further transgressions against collective values can erode institutional legitimacy.

In group communication settings individuals are able to identify the important collective outcomes of decisions, which helps articulate and reinforce collectively held values to achieve collective goals and overcome any potential free-rider effects. Although the survey results reveal low trust levels among respondents and priority placed upon cultural and 
environmental attributes, the effects of group communication reveals a recognition that there is an important collective aspect to economic involvement that also brings collective benefits beyond just individual benefits. In this study Tourism Promotion represented more intermediate socio-economic outcomes with moderate ecological and associated cultural impacts than the two other alternatives, offering more collective benefits. This preference may also capture nascent efforts of these First Nations to rebuild their governance and economic systems. Ostrom (2006) observes that reaching consensus and sustaining cooperation through communication is dependent on the level to which group members are homogenous and self-identify with the group, and part of the effect of communication may be to re-inforce self-identification, that here-to-for has been weak or absent.

An important insight for practice is that individual surveys to understand IPs land use preferences cannot always be aggregated to determine collective land use preferences. Rather, these individual preferences may be subject to change through communication and collective deliberation, and any research design should account for this by producing collective decision making processes, where these are relevant, to better understand land use preferences. These collective decision making processes will not be homogenous for all IPs, they will be unique and reflect local institutions, norms and values. Thus, an important objective of further research should be to assess the kinds of collective deliberation processes IPs may use (and prefer), the degree to which these reinforce local values and norms, and whether other aspects of group deliberation influence the 'free will' of individuals. This last point is particularly important as processes for FPIC are implemented - to maintain the integrity of consent processes, it will be important to ensure that individuals are not coerced and give their consent freely, and how this fits with collective deliberation processes needs close attention. Also, another area for inquiry is whether collective decision making processes must occur in ways that are considered 'traditional' to foster cooperation, or what Cornell and Kalt (2000) describes as a 'cultural match', or can new forms of structure and institutions (or more 'Western' forms) achieve similar results of cooperation. 


\section{References}

Anderson, R.B., Dana, L.P., and Dana, T. E. (2006). Indigenous Land Rights, Entrepreneurship, and Economic Development in Canada: 'Opting-in' to the Global Economy, Journal of World Business, 41(1), 45-55.

Atleo, E. R. (2007). Tsawalk: A Nuu-chah-nulth worldview. Vancouver: Canada: UBC Press.

Bliemer, M. C., Rose, J. M., and Hess, S. (2008). Approximation of Bayesian efficiency in experimental choice designs. Journal of Choice Modelling, 1(1), 98-126.

Bodley, J. (1998). The victims of progress ( $4^{\text {th }}$ Edn). San Francisco: McGraw-Hill.

Burleigh, T. J., and Meegan, D. V. (2013). Keeping up with the Joneses affects perceptions of distributive justice. Social Justice Research, 26(2), 120-131.

Cardenas, J. C., and Ostrom, E. (2004). What do people bring into the game? Experiments in the field about cooperation in the commons. Agricultural Systems, 82(3), 307-326.

Carson, R. T., and Groves, T. (2007). Incentive and informational properties of preference questions. Environmental and Resource Economics, 37(1), 181-210.

Coleman, J. S. (1966). Foundations for a theory of collective decisions. American Journal of Sociology, 71 (6): 615-627.

Cornell, S., and Kalt, J. P. (2000). Where's the glue? Institutional and cultural foundations of American Indian economic development. The Journal of Socio-Economics, 29(5), 443-470.

Doyle, C. M. (2014). Indigenous Peoples, Title to Territory, Rights and Resources: The Transformative Role of Free Prior and Informed Consent. Oxon, UK: Routledge.

Fehr, E. (2004). Don't lose your reputation. Nature, 432, 449-450.

Fiebig, D.G., Keane, M.P., Louviere, J., and Wasi, N. (2010). The generalized multinomial logit model: accounting for scale and coefficient heterogeneity. Marketing Science, 29 (3): 393-421.

Fishburn, P. (1988). Utility Theory. New York: John Wiley \& Sons.

Giddings, B., Hopwood, B., and O'Brien, G. (2002). Environment, economy and society: fitting them together into sustainable development. Sustainable Development, 10 (4): 187-196.

Greene, W. H., and Hensher, D. A. (2010). Does scale heterogeneity across individuals matter? An empirical assessment of alternative logit models. Transportation, 37(3), 413-428.

Gregory, R. S. (2000). Valuing environmental policy options: a case study comparison of multi-attribute and contingent valuation survey methods. Land Economics, 76 (2):151-173.

Gregory, R., and Trousdale, W. (2009). Compensating aboriginal cultural losses: an alternative approach to assessing environmental damages. Journal of Environmental Management 90: 2469-2479.

Hayter, R., and Barnes, T. J. (2012). Neoliberalization and its geographic limits: Comparative reflections from forest peripheries in the Global North. Economic Geography, 88(2), 197-221.

Hensher, D. A., and Greene, W. H. (2003). The mixed logit model: the state of practice. Transportation, 30(2), 133-176.

Hensher, D. A., Rose, J. M., and Greene, W. H. (2005). Applied choice analysis: a primer. Cambridge University Press, Cambridge, UK.

Hensher, D. A., Rose, J. M., and Li, Z. (2012). Does the choice model method and/or the data matter? Transportation, 39(2), 351-385. 
Horne, P. (2006). Forest owners' acceptance of incentive based policy instruments in forest biodiversity conservation - a choice experiment based approach. Silva Fennica, 40(1): $169-178$.

Janis, I. L. (1971). Groupthink, Psychology Today, 5, November, 43-46 \& 74-76.

Janis, I. L. (1982). Groupthink (2nd Ed.). Boston: Houghton Mifflin.

Kerr, N.L., and Kauffman- Gilliland, C.M. (1994). Communication, commitment and cooperation in social dilemma. Journal of Personality and Psychology, 66 (3), 513529.

Lertzman, D. A., and Vredenburg, H. (2005). Indigenous peoples, resource extraction and sustainable development: an ethical approach. Journal of Business Ethics, 56(3), 239254.

Louviere, J. J., Hensher, D. A., and Swait, J. D. (2000). Stated choice methods: analysis and applications. Cambridge UK, Cambridge University Press.

Masso, M. (2005) Tla-o-qui-aht Nation Building Strategy: Ha'wiih and Ma'uas (Chiefs and Houses), Masters Thesis, University of Victoria, Victoria BC. Available at: <http://web.uvic.ca/igov/research/pdfs/598_Sayachapis.pdf> (accessed on July 21, 2014).

Nikolakis, W. (2010) Barriers to Indigenous Enterprise Development on Communally Owned Land. Global Business and Economics Review, 12(1/2), 85-99.

Nikolakis, W., and Grafton, R.Q. (2014). Fairness and Justice in Indigenous Water Allocations: Insights from Northern Australia. Water Policy, 16 (S2), 19-35.

Nikolakis, W., and Grafton, R.Q. (2015). Putting Indigenous Water Rights to Work: The Sustainable Livelihoods Framework as a Lens for Remote Development. Community Development, DOI:10.1080/15575330.2015.1009922.

Nikolakis, W., Grafton, R.Q. and To, H. (2013). Indigenous Values and Water Markets: Survey Insights from Northern Australia, Journal of Hydrology, 500: 12-20.

Nikolakis, W., and Nelson, H. (2015). To Log or Not to Log? How Forestry Fits with the Goals of First Nations in British Columbia. Canadian Journal of Forest Research, 10.1139/cjfr-2014-0349

Nikolakis, W., Nelson, H., and Cohen, D. (2014) Who Pays Attention to Indigenous Peoples in Sustainable Development and Why? Evidence from Socially Responsible Investment Mutual Funds in North America. Organization and Environment, 27 (4), 368-382.

Ostrom, E. (1998). A behavioral approach to the rational choice theory of collective action. American Political Science Review 92, 1-22.

Ostrom, E. (2006). The value-added of laboratory experiments for the study of institutions and common-pool resources. Journal of Economic Behavior and Organization 61(2): $149-163$.

Ostrom, E. (2010). Beyond markets and states: polycentric governance of complex economic systems. Transnational Corporations Review 2 (2): 1-12.

Personal communication. (2014). Question of researcher answered by member of Ahousaht with personal knowledge, February, 2014.

Postmes, T., Spears, R., and Cihangir, S. (2001). Quality of decision making and group norms. Journal of Personality and Social Psychology, 80(6), 918.

Rolfe, J.C., and Windle, J. (2003). Valuing the protection of aboriginal cultural heritage sites. The Economic Record 79, S85-S95 (Special Issue).

Sally, D. (1995). Conversation and cooperation in social dilemmas: a meta-analysis of experiments from 1958 to 1992. Rationality and Society 7, 58-92.

Spyce, A., Weber, M., and Adamowicz, W. (2012). Cumulative Effects Planning: Finding the Balance Using Choice Experiments. Ecology \& Society, 17(1):22-32. 
Statistics Canada. (2013). Marktosis 15, IRI, British Columbia (Code 5923808) (table). National Household Survey (NHS) Profile. 2011 National Household Survey. Statistics Canada Catalogue no. 99-004-XWE. Ottawa. Released September 11, $2013 . \quad \quad<$ http://www12.statcan.gc.ca/nhs-enm/2011/dp$\mathrm{pd} /$ prof/index.cfm?Lang=E $>$ (accessed July 22, 2014).

Statistics Canada. (2013). Opitsat 1, IRI, British Columbia (Code 5923813) (table). National Household Survey (NHS) Profile. 2011 National Household Survey. Statistics Canada Catalogue no. 99-004-XWE. Ottawa. Released

September 11, 2013.<http://www12.statcan.gc.ca/nhs-enm/2011/dp$\mathrm{pd} /$ prof/index.cfm?Lang=E $>$ (accessed July 22, 2014).

Swait, J., and Louviere, J. (1993). The role of the scale parameter in the estimation and comparison of multinomial logit models. Journal of Marketing Research, 30 (3): 305314.

Turner, J. C. (1991). Social Influence. Belmont CA, US, Thomson Brooks/Cole Publishing Co.

United Nations Declaration on the Rights of Indigenous Peoples (UNDRIP). (2008). Resolution adopted by the General Assembly, 61/295, Available at: <www.un.org/esa/socdev/unpfii/documents/DRIPS_en.pdf.> (accessed 2 March 2014).

Venn, T. J., \& Quiggin, J. (2007). Accommodating indigenous cultural heritage values in resource assessment: Cape York Peninsula and the Murray-Darling Basin, Australia. Ecological Economics, 61(2), 334-344.

Wilson, K., and Peters, E. J. (2005). You can make a place for it": Remapping urban First Nations spaces of identity. Environment and Planning D: Society and Space, 23(3), 395-413.

Wondolleck, J. (1985). The importance of process in resolving environmental disputes. Environmental Impact Assessment Review, 5(4), 341-356.

Wondolleck, J. M., and Yaffee, S. L. (2000). Making collaboration work: Lessons from innovation in natural resource management. Washington, D.C.: Island Press.

Wuttunee, W. (2004) Living Rhythms: Lessons in Aboriginal Economic Resilience and Vision. Montreal: McGill-Queen's University Press.

Zander, K. K., and Garnett, S. T. (2011). The economic value of environmental services on indigenous-held lands in Australia. PloS one, 6(8), e23154.

Zander, K. K., Garnett, S. T., and Straton, A. (2010). Trade-offs between development, culture and conservation-willingness to pay for tropical river management among urban Australians. Journal of Environmental Management, 91(12), 2519-2528.

Zander, K. K., and Straton, A. (2010). An economic assessment of the value of tropical river ecosystem services: Heterogeneous preferences among Aboriginal and nonAboriginal Australians. Ecological Economics, 69(12), 2417-2426. 
Figure 1 Example of a choice question

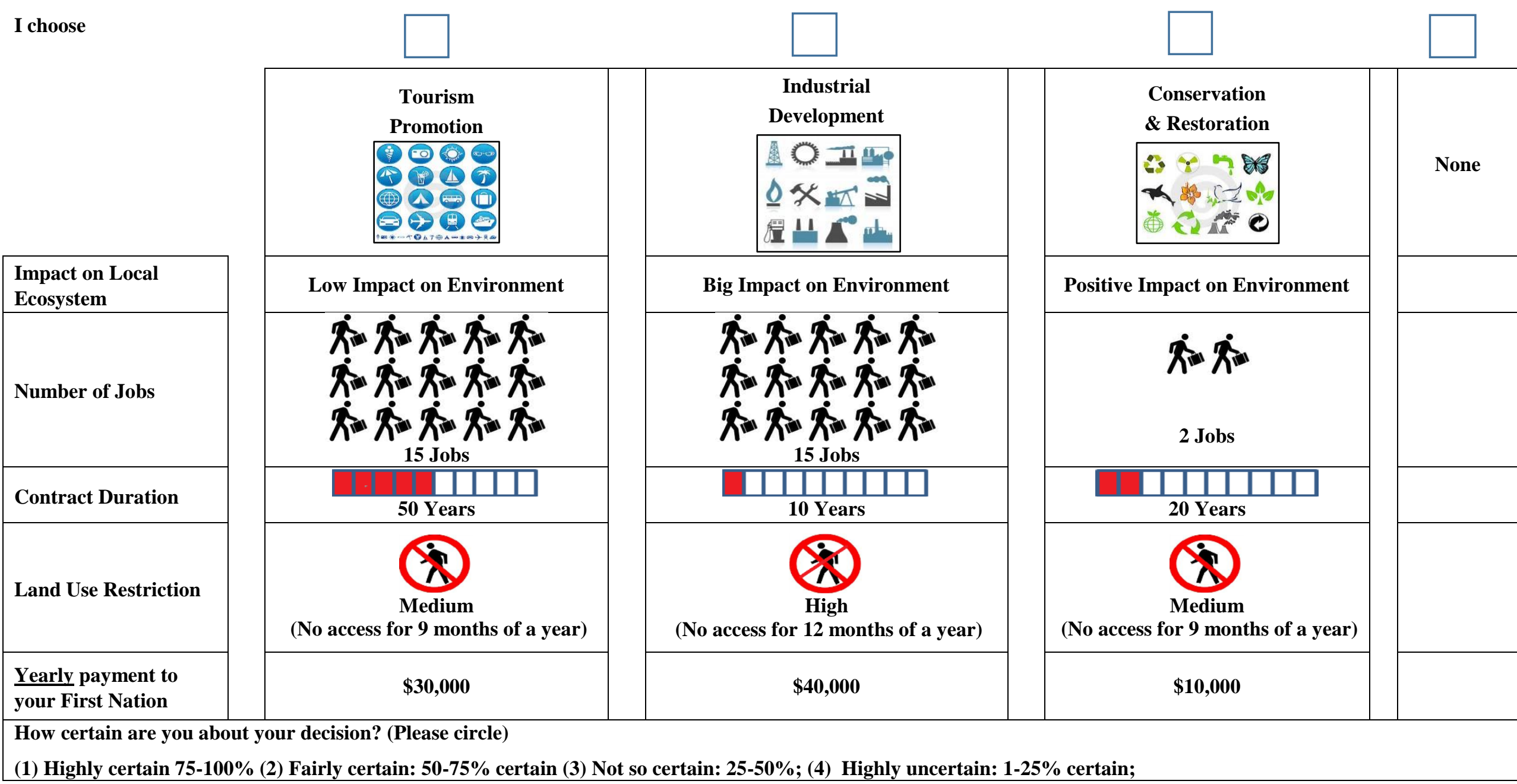


Figure 2a Votes for land use alternatives in Rounds I and II

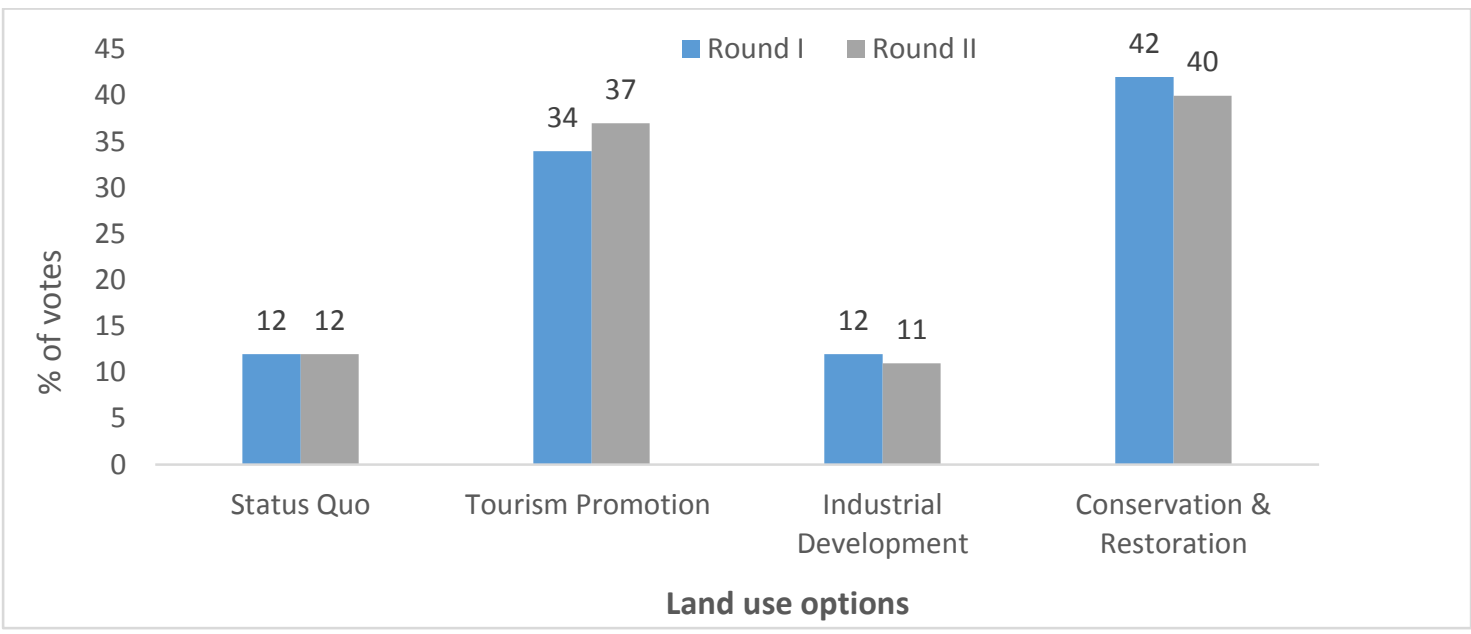

Figure 2b Changes in votes for land use alternatives from Rounds I to II between Treatment and Control groups

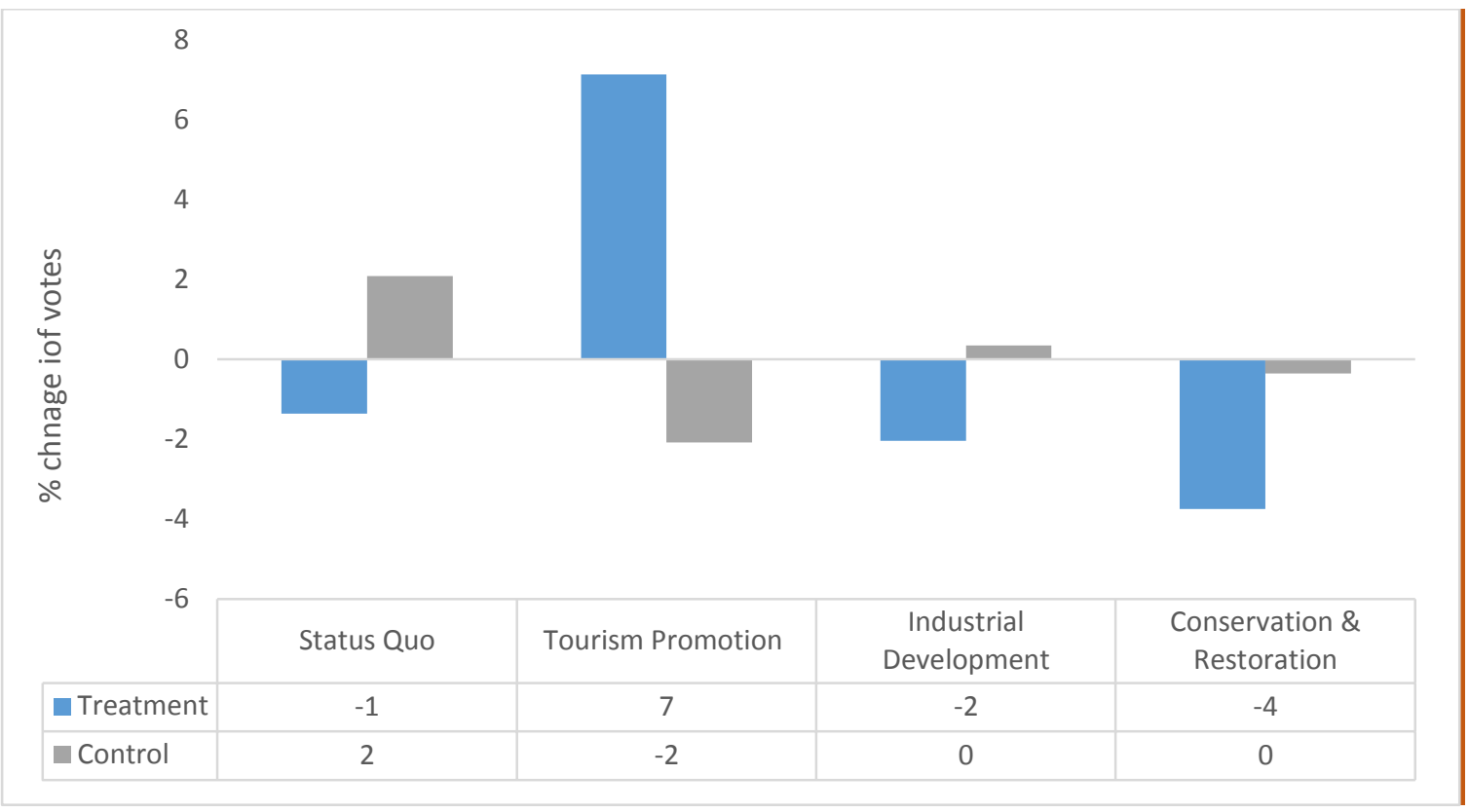

Figure 3 Votes for land use alternatives across First Nations communities

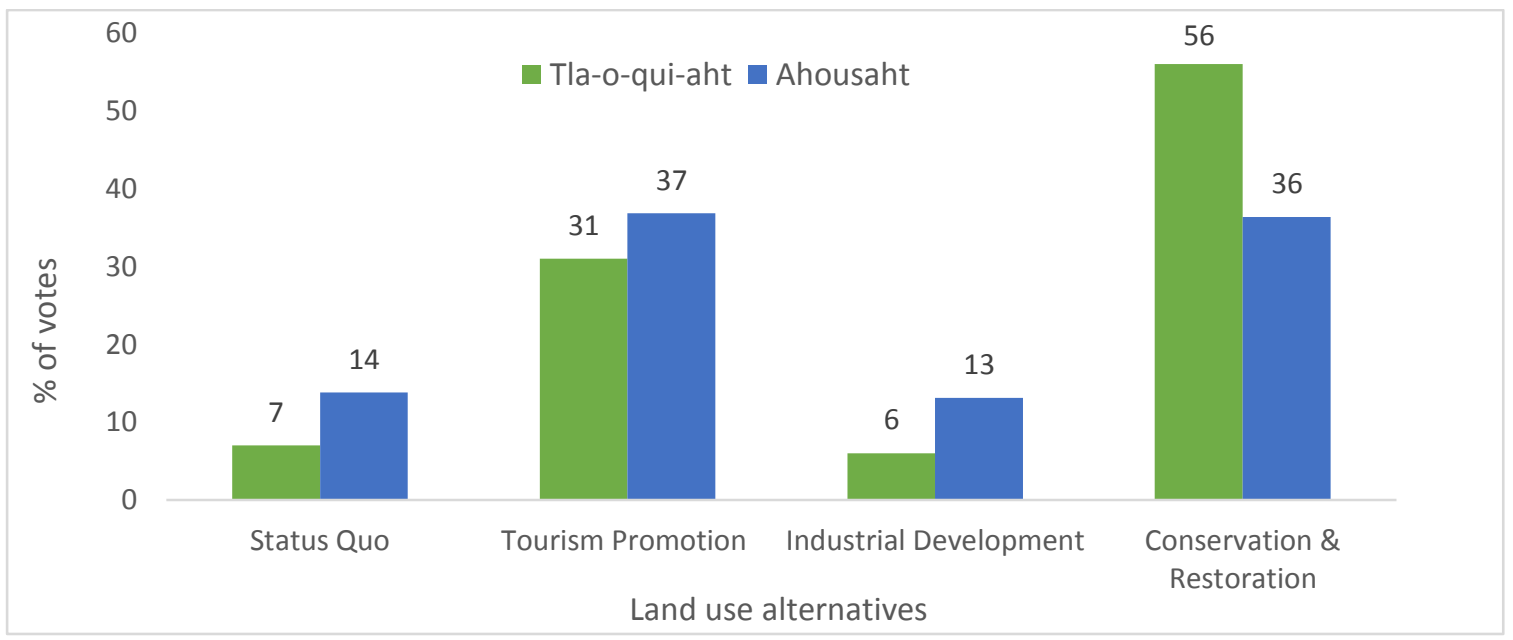




\begin{tabular}{|c|c|c|c|c|c|}
\hline Attributes & Definition & Tourism Promotion & Industrial Development & $\begin{array}{l}\text { Conservation and } \\
\text { Restoration }\end{array}$ & Source of prior \\
\hline Jobs & $\begin{array}{l}\text { Jobs made available to members } \\
\text { of the First Nation }\end{array}$ & $5,8,10,15$ & $5,8,10,15$ & $2,5,8,10$ & Spyce et al. (2012) \\
\hline
\end{tabular}

Table 1 Attributes and their levels 


\begin{tabular}{|c|c|c|c|c|c|}
\hline \multirow[t]{2}{*}{ Compensation } & Compensation paid to the First & 10,$000 ; 20,000 ; 30,000$ & 30,$000 ; 40,000 ; 50,000$ & 10,$000 ; 20,000 ; 30,000$ & Horne (2006) \\
\hline & Nation per year & $40000 ; 50,000$ & 80,$000 ; 100,000$ & $40000 ; 50,000$ & \\
\hline Contract & $\begin{array}{l}\text { The number of years the } \\
\text { arrangement will be in place }\end{array}$ & $10,20,30,40,50$ & $10,20,30,40,50$ & $20,30,50,80,100$ & Horne (2006) \\
\hline Restriction & $\begin{array}{l}\text { The number of months per year } \\
\text { the area cannot be accessed by } \\
\text { members of the First Nation }\end{array}$ & High, Medium, Low & High, Medium, Low & High, Medium, Low & Horne (2006) \\
\hline
\end{tabular}


Table 2 Quasi experimental setting

\begin{tabular}{lcc}
\hline First Nations & $\begin{array}{c}\text { Treatment } \\
\text { (with communication) }\end{array}$ & $\begin{array}{c}\text { Control } \\
\text { (without communication) }\end{array}$ \\
\hline Tla-o-qui-aht & Round I & Round I \\
& Round II & Round II \\
\hline $\begin{array}{l}\text { Ahousaht } \\
\text { (On reserve) }\end{array}$ & Round I & Round I \\
& Round II & 20 minutes interval \\
& & \\
\hline $\begin{array}{l}\text { Ahousaht } \\
\text { (Off reserve })\end{array}$ & Round I & Round II \\
& 20 minutes interval & \\
\hline
\end{tabular}


Table 3 Generalized mixed logit regression results

\begin{tabular}{|c|c|c|}
\hline & $\begin{array}{c}\text { Coefficient } \\
(\mathrm{SE})\end{array}$ & $\begin{array}{c}\mathrm{SD} \\
(\mathrm{SE}) \\
\end{array}$ \\
\hline \multicolumn{3}{|l|}{ Random parameters } \\
\hline ASC (Tourism Promotion) ${ }^{\mathrm{a}}$ & $\begin{array}{c}2.00 * * * \\
(0.52)\end{array}$ & $\begin{array}{c}0.41 \\
(0.33)\end{array}$ \\
\hline ASC (Industrial Development) ${ }^{\mathrm{a}}$ & $\begin{array}{c}-6.98 * * * \\
(1.83)\end{array}$ & $\begin{array}{c}3.12 * * * \\
(1.57)\end{array}$ \\
\hline ASC (Conservation \& Restoration $)^{\mathrm{a}}$ & $\begin{array}{c}0.55 \\
(0.41)\end{array}$ & $\begin{array}{c}4.21 * * * \\
(0.61)\end{array}$ \\
\hline Restriction $($ high $=3$, medium $=2$, low $=1$, none $=0$ ) & $\begin{array}{c}-1.43 * * * \\
(0.30)\end{array}$ & $\begin{array}{c}1.92 * * * \\
(0.28)\end{array}$ \\
\hline \multicolumn{3}{|l|}{ Constant parameters } \\
\hline Jobs (Tourism Promotion) & $\begin{array}{c}0.05 * * * \\
(0.015)\end{array}$ & \\
\hline Jobs (Industrial Development) & $\begin{array}{c}0.19 * * * \\
(0.03)\end{array}$ & \\
\hline Jobs (Conservation \& Restoration) & $\begin{array}{c}0.15 * * * \\
(0.02)\end{array}$ & \\
\hline Length of contract (in years) & $\begin{array}{c}0.01 * * * \\
(0.002)\end{array}$ & \\
\hline Compensation (Tourism Promotion and Conservation \& Restoration) & $\begin{array}{c}0.018 * * * \\
(0.003)\end{array}$ & \\
\hline Compensation (Industrial Development) & $\begin{array}{c}0.01 * \\
(0.005) \\
\end{array}$ & \\
\hline \multicolumn{3}{|l|}{ Treatment effect } \\
\hline${ }^{\mathrm{b}}$ Round II*ASC (Tourism Promotion) & $\begin{array}{c}0.27 \\
(0.32)\end{array}$ & \\
\hline${ }^{\mathrm{b}}$ Round II*ASC (Industrial Development) & $\begin{array}{c}0.60 \\
(0.60)\end{array}$ & \\
\hline${ }^{\mathrm{b}}$ Round II*ASC (Conservation \& Restoration) & $\begin{array}{c}0.33 \\
(0.30)\end{array}$ & \\
\hline${ }^{\mathrm{c}}$ Round II*Treatment*ASC (Tourism Promotion) & $\begin{array}{c}0.91 * * \\
(0.41)\end{array}$ & \\
\hline${ }^{\mathrm{c}}$ Round II*Treatment*ASC (Industrial Development) & $\begin{array}{l}-0.22 \\
(0.71)\end{array}$ & \\
\hline${ }^{\mathrm{c}}$ Round II*Treatment*ASC (Conservation \& Restoration) & $\begin{array}{c}0.42 \\
(0.46) \\
\end{array}$ & \\
\hline \multicolumn{3}{|l|}{ Structural parameters } \\
\hline$\tau$ & $\begin{array}{c}1.60 * * * \\
(0.17)\end{array}$ & \\
\hline$\eta$ & $\begin{array}{c}-0.48 * * * \\
(0.13)\end{array}$ & \\
\hline$\gamma$ & $\begin{array}{c}0.67 \mathrm{D}-06 \\
0.06\end{array}$ & \\
\hline$\sigma$ & $\begin{array}{c}1.00 \\
(2.10) \\
\end{array}$ & \\
\hline \multicolumn{3}{|l|}{ Model statistics } \\
\hline Number of groups & \multicolumn{2}{|c|}{97} \\
\hline Number of replications & \multicolumn{2}{|c|}{100} \\
\hline Log likelihood & \multicolumn{2}{|c|}{-971} \\
\hline $\mathrm{LR} \mathrm{Chi}^{2}$ & \multicolumn{2}{|c|}{$1285(\mathrm{df}=23, p<0.001)$} \\
\hline McFadden Pseudo $\mathrm{R}^{2}$ & \multicolumn{2}{|c|}{0.40} \\
\hline
\end{tabular}


$\mathrm{AIC}$

Notes:

$* * *: \mathrm{p}<0.01 ; * *: \mathrm{p}<0.05 ; *: \mathrm{p}<0.10$. ${ }^{\mathrm{a}}$ Base category=Status quo. ${ }^{\mathrm{b}}$ Base category=Round I. ${ }^{\mathrm{c}}$ Base category $=$ Round II*Control 
Table 4 Mean implicit prices of the land use attributes $(C \$$ per year)

\begin{tabular}{|c|c|c|}
\hline Attribute & Units & $\begin{array}{l}\text { Mean implicit prices } \\
\text { (95\% confidence interval) }\end{array}$ \\
\hline Jobs (Tourism Promotion) & $\mathrm{C} \$$ per job & $\begin{array}{c}2,753 \\
(576-4,929)\end{array}$ \\
\hline Jobs (Industrial Development) & $\mathrm{C} \$$ per job & $\begin{array}{c}19,749 \\
(-5,500-44,999)\end{array}$ \\
\hline $\begin{array}{l}\text { Jobs (Conservation \& } \\
\text { Restoration) }\end{array}$ & $\mathrm{C} \$$ per job & $\begin{array}{c}8,415 \\
(4,631-12,200)\end{array}$ \\
\hline $\begin{array}{l}\text { Contract (Industrial } \\
\text { Development) }\end{array}$ & $\mathrm{C} \$$ one extra year of contract & $\begin{array}{c}1,129 \\
(-78-2,335)\end{array}$ \\
\hline $\begin{array}{l}\text { Contract (Conservation \& } \\
\text { Restoration and Tourism } \\
\text { Promotion) }\end{array}$ & $\mathrm{C} \$$ one extra year of contract & $\begin{array}{c}600 \\
(218-983)\end{array}$ \\
\hline $\begin{array}{l}\text { Restriction (Industrial } \\
\text { Development) }\end{array}$ & $\begin{array}{l}\text { C\$ per level } \\
\text { (none-low-medium-high) }\end{array}$ & $\begin{array}{c}-38,067 \\
(-56,183)-(-19,952)\end{array}$ \\
\hline $\begin{array}{l}\text { Restriction (Conservation \& } \\
\text { Restoration and Tourism } \\
\text { Promotion) }\end{array}$ & $\begin{array}{l}\mathrm{C} \$ \text { per level } \\
\text { (none-low-medium-high) }\end{array}$ & $\begin{array}{c}-80,533 \\
(-124,096)-(-36,970)\end{array}$ \\
\hline
\end{tabular}


Table 5 Mean compensating surplus (CS) derived from the land use alternatives (C\$/year)

\begin{tabular}{lc}
\hline Land use alternatives & $\begin{array}{c}\text { Mean Compensating Surplus } \\
(95 \% \text { confidence interval })\end{array}$ \\
\hline Tourism Development & 58,133 \\
& $(12,471-103,795)$ \\
Industrial Development & $-797,146$ \\
Conservation and Restoration & $(-1,818,164)-(223,870)$ \\
& -722 \\
\end{tabular}

Notes: CS calculated for the following attribute values: Jobs=3; Contract=30 years; Restriction=Low 


\section{Appendix A. Ahousaht and Tla-o-qui-aht Demographic Data}

In Tla-o-qui-aht's main village of Opitsaht there were 155 residents in the most recent census, including 90 males and 65 females. Of these 155, some 95 were over 19 years of age and 36.4 percent were employed. Statistics Canada was unable to provide income data for Opitsaht (Statistics Canada, 2013). All of those working in Opitsaht were employed full time, shared equally between agriculture, forestry and fishing, retail trades, accommodation and food services, and public administration (Statistics Canada, 2013). There are another 175 members of Tla-o-qui-aht that live off reserve, making for a total of 330 members (Statistics Canada, 2013).

In Ahousaht's main village of Marktosis there were 725 residents, 370 males and 355 females, and the vast majority having lived there for three generations or more. Of these 725, 396 were over 19 years of age, and 49.5 percent were employed and the average income was $\$ 20,583$. This income level places an estimated 605 of the 725 residents in Marktosis, in the bottom half of the Canadian distribution of adjusted after-tax family income (Statistics Canada, 2013a).

Government services were the biggest employer ( 85 people) followed by education services ( 45 people), health services (35) then agriculture forestry and fishing (25 people) (Statistics Canada, 2013a). Most of the employment is part time, with only 105, of the 230 people employed in 2010 working full time. Additionally, 927 Ahousaht live off-reserve of a voting age scattered across $\mathrm{BC}$ and the US (pers. comm, 2014), for which data is difficult to aggregate.

\section{Appendix B. Description of choice scenario}

We will now ask you SIX questions about future land management options in Clayoquot Sound (with focus on your nation's territory).

Each question will ask you to choose among the following three different options for land management in your nation's territory:

1. Tourism Promotion means increased tourist numbers, accommodation, restaurants and tours. These will have a small negative impact on Clayoquot's local ecosystems.

2. Industrial Development means an increase in mining and logging activities. These will have a substantial negative impact on local ecosystems.

3. Conservation and Restoration means improved forest conservation and salmon habitat restoration. These will have a substantial positive impact on local ecosystems.

Each program will deliver different monetary $(\$)$ and non-monetary benefits (jobs and environmental outcomes) to your First Nations. However, different choices may restrict your Nation's members' access to territory during the period of the contract.

- $\underline{\text { High restriction }}=$ no access of First Nations

- Medium restriction = some access for part of the year, but restrictions on cultural and traditional use (such as hunting and fishing)

- Low restriction $=$ access allowed but may be limited at times.

Please carefully compare the alternatives with respect to the number of jobs, the payment (\$) to the First Nations, restriction on land access and the length of contract. Also, please consider the environmental impacts of your choice. 
Please let us know if you have any question about the programs.

Next, we will present you SIX questions. We would like you to vote for the alternative you like most in each of the six questions. If you don't like any tick "None". The program that receives highest votes will be recommended for implementation.

\section{Appendix C. Administration of Surveys}

The experiment was applied in the two First Nations in one-day sessions during 2013 (August on reserve in Ahousaht and Tla-o-qui-aht in September) and 2014 (January and March for offreserve Ahousaht groups from Port Alberni/Victoria). Three control group and three treatment groups were conducted for a total of six survey sessions. Each session lasted one and a half hours on average.

At the beginning of each session the respondents were told by a researcher that they would be given six-choice questions that would ask for their land use preferences in the form of a vote, and the land use option that received the highest votes would be implemented for the whole group. The respondents were given instructions on each of the attributes and what these meant. The respondents were told that the researchers were available to assist with any questions from the respondents.

The first control group session was held at the Band Council offices on Opitsaht, Tla-o-qui-aht's largest reserve. Thirteen individuals attended the control group session, which included three sub-groups of 4, 4 and 5. Individuals were randomly allocated to the sub-groups. As was protocol, three researchers instructed the group on the purpose of the survey (including a brief overview of payment for ecosystem services and the format of the choice survey). The treatment group session was held at Tla-o-qui-aht's treaty office. The structure of the sub-groups were 5, 4 and 3 ( 1 of the surveys in the group of 3 could not be used as the participant could not complete the survey). The instructions to this group followed that of the control group, however, upon completing Round I of the survey the participants were told that they had 20 minutes to discuss their answers and to consult with the researcher. The groups seemed a little reluctant to discuss their answers at first, however, once we engaged respondents in discussion debates flowed and people sought to justify and argue the reasons for choosing their responses.

In Ahousaht on reserve, the surveys were conducted at a three rooms set aside at the local medical clinic. In the morning, a group of 5, 6 and 6 participants ( 2 of the surveys were not usable) completed the control survey. The treatment group was also divided in three sub-groups in three different rooms, with 6 participants in each group (and 1 of the surveys was not usable). During the 15 minute discussion there was lively discussion on the answers particularly given the relevance of mining and forestry issues in the community. The issues raised included the need to address poverty in communities and the need for jobs through industrial development, however there was also acknowledged the tension of wanting to act as stewards for the land.

The Ahousaht off reserve control group had 7,6 and 7 individuals. The sessions were held outside of work hours (lunch and evening), because off-reserve members were more likely to have full time jobs that required them in the office from 9 am to $5 \mathrm{pm}$. In the treatment group in 
the evening there were three groups again with 7, 5 and 8 members ( 2 surveys could not be used from the group of 5 as they were not complete). Discussion was lively again with participants debating the need for economic development and the desire to conserve the land base. The participants, most whom worked full time, also lamented their lack of involvement in decision making for their Nation (because they were not living on reserve in their territories). They wanted better engagement with the First Nation.

\section{Appendix D. Sample characteristics}

\begin{tabular}{|c|c|c|c|}
\hline & Tla-o-qui-aht & $\begin{array}{c}\text { Ahousaht } \\
\text { (On-reserve) }\end{array}$ & $\begin{array}{c}\text { Ahousaht } \\
\text { (Off-reserve) }\end{array}$ \\
\hline Sample size & 25 & 33 & 39 \\
\hline Female $(\%)$ & 44 & 42 & 54 \\
\hline Average age (years) & 43 & 46 & 48 \\
\hline Secondary education and above $(\%)$ & 60 & 48 & 46 \\
\hline $\begin{array}{l}\text { Average (median) gross income p.a } \\
\text { (C\$) }\end{array}$ & 45,000 & 45,000 & 30,000 \\
\hline Employed $(\%)$ & 80 & 73 & 49 \\
\hline Looking for work (\%) & 16 & 40 & 41 \\
\hline Average (median) household size & 4 & 3 & 3 \\
\hline $\begin{array}{l}\text { Number of respondents with individual } \\
\text { land ownership }\end{array}$ & 1 & 7 & 7 \\
\hline $\begin{array}{l}\text { Number of respondents with official } \\
\text { positions in FN council }\end{array}$ & 7 & 3 & 2 \\
\hline $\begin{array}{l}\text { Number of respondents with traditional } \\
\text { decision making power }\end{array}$ & 5 & 12 & 5 \\
\hline
\end{tabular}


Appendix E. Results of the main-effect model (random parameter logit).

\begin{tabular}{|c|c|c|}
\hline & $\begin{array}{c}\text { Coefficient } \\
(\mathrm{SE})\end{array}$ & $\begin{array}{l}\text { SD } \\
(\mathrm{SE}) \\
\end{array}$ \\
\hline \multicolumn{3}{|l|}{ Random parameters } \\
\hline Compensation (Conservation \& Restoration and Tourism & $0.012 * * *$ & $0.012 * * *$ \\
\hline Promotion) & $(0.004)$ & $(.004)$ \\
\hline Compensation (Industrial Development) & $\begin{array}{c}0.024 * * * \\
(0.004)\end{array}$ & $\begin{array}{c}0.024 * * * \\
(0.004)\end{array}$ \\
\hline Restriction (high $=3$, medium $=2$, low $=1$, none $=0$ ) & $\begin{array}{c}-0.90 * * * \\
(0.19)\end{array}$ & $\begin{array}{c}1.43 * * * \\
(0.16)\end{array}$ \\
\hline \multicolumn{3}{|l|}{ Constant parameters } \\
\hline Jobs (Tourism Promotion) & $\begin{array}{c}0.013 \\
(0.018)\end{array}$ & - \\
\hline Jobs (Industrial Development) & $\begin{array}{c}0.11 * * * \\
(0.03)\end{array}$ & - \\
\hline Jobs (Conservation \& Restoration) & $\begin{array}{c}0.06 * * * \\
(0.024)\end{array}$ & - \\
\hline Length of contract (in years) & $\begin{array}{c}0.005 * * \\
(0.002)\end{array}$ & - \\
\hline ASC (Tourism Promotion) ${ }^{\mathrm{a}}$ & $\begin{array}{c}2.51 * * * \\
(0.30)\end{array}$ & - \\
\hline ASC (Industrial Development) ${ }^{\mathrm{a}}$ & $\begin{array}{l}-0.73 \\
(0.50)\end{array}$ & - \\
\hline ASC (Conservation \& Restoration) $^{\mathrm{a}}$ & $\begin{array}{c}2.34 * * * \\
(0.28)\end{array}$ & - \\
\hline
\end{tabular}

Notes: ***: $\mathrm{p}<0.01 ; * *: \mathrm{p}<0.05$.

${ }^{\mathrm{a}}$ Base category $=$ Status quo. 